\title{
CLINICAL FACTORS ADVERSELY AFFECTING EARLY OUTCOME AFTER BRAIN INFARCTION
}

\author{
CHARLES ANDRÉ*, SÉRGIO A.P. NOVIS*
}

\begin{abstract}
SUMMARY - Purpose and methods: One-hundred-and-nine consecutive patients admitted during the acute phase of a CT-confirmed brain infarction (BI) were studied. Putative adverse influence of demographic and stroke risk factors, previous medical history, clinical presentation, initial and follow-up neurological examination, initial general evaluation, laboratory findings, chest X-ray and electrocardiographic findings, treatment, and topography and etiology of the ischemic insult was analysed. The end-point for assessment was early death (within $\mathbf{3 0}$ days). Statistical analysis was performed with univariate analysis and multiple regression. Results: The main adverse factors related to an increased death risk during the first 30 days were, in decreasing order of importance: coma 48-72 hours after admission; stroke occuring in already hospitalized patients; Babinski sign on admission; minor degrees of impairment of consciousness 48-72 hours after admission; stroke related to large artery atherothrombosis and to embolism; a history of early impairment of consciousness; cardiac failure on admission. In 53 lucid patients on admission, only a history of congestive heart failure (CHF) was associated with a reduced survival rate. In 56 patients with impaired consciousness, the presence of a Babinski sign increased death risk, but the main factor predicting a high case-fatality rate was the persistence of consciousness disturbances after 48-72 hours. Conclusions: The presence of impairment of consciousness, especially coma, 2-3 days after disease onset, and a history of CHF greatly increase the early case fatality rate in patients with acute BI presenting with or without consciousness disturbances at admission, respectively. The use of a prognostic algorythm considering these few variables seems to predict the approximate 30-day fatality rates.
\end{abstract}

KEY WORDS: cerebral infarction, coma, death, heart failure (congestive), prognosis.

\section{Determinantes clínicos do risco de vida na fase aguda do infarto cerebral}

RESUMO - Foram estudados 109 pacientes internados na fase aguda do infarto encefálico. Foi investigada a possível influência prognóstica adversa de diversos aspectos da história epidemiológica e médica, apresentação clínica, exame neurológico de admissão e sequencial, exame clínico geral, exames radiológicos, laboratoriais e eletrocardiograma, tratamento, topografia e mecanismo etiopatogênico da lesão isquêmica sobre o risco de vida nos primeiros 30 dias de doença. Foram feitas análises estatísticas de univariância e regressão múltipla. Resultados: Os primeiros fatores prognósticos adversos encontrados foram: coma 48-72 horas após a admissão; infarto intra-hospitalar; sinal de Babinski ao exame inicial; graus menores de depressão da consciência; infarto por aterotrombose de grandes vasos ou por embolização; história de alteração precoce da consciência; falência cardíaca à admissão. Em pacientes lúcidos à internação ( 53 casos), somente história de insuficiência cardíaca associou-se a aumento da mortalidade. Em 56 casos com alteração da consciência, a presença do sinal de Babinski aumentou o risco de vida, mas o principal fator adverso foi a persistência do distúrbio de consciência após 48-72 horas. Conclusões: A presença de depressão da consciência, em especial o coma, 2-3 dias após o início da doença, e história de insuficiência cardíaca aumentam grandemente o risco de vida na fase aguda do infarto cerebral. A utilização de um algoritmo prognóstico simples considerando estas variáveis torna mais objetiva a previsão do risco de vida após o infarto.

PALAVRAS-CHAVE: infarto cerebral, coma, morte, insuficiência cardíaca (congestiva), prognóstico.

Brain infarction (BI) is responsible for most deaths following cerebrovascular disease $e^{6,15,23,36,38}$. Case fatality rates after BI vary widely in different studies, and seem to depend mainly on series

* M.D. From the Department of Neurology, Hospital Universitário Clementino Fraga Filho (HUCFF), Federal University of Rio de Janeiro (UFRJ), Rio de Janeiro. Aceite: 7-outubro-1993.

Dr. Charles André - Rua Real Grandeza 139 sala 202 - 22281-030 Rio de Janeiro RJ - Brasil. 
composition- extension of neurological insult, presence and degree of consciousness impairment ${ }^{8,10,22,28,29,31,37,38}$. Few authors stressed the importance of extraneurological factors, especially cardiac comorbidity ${ }^{7,13,22,23,33}$, in the determination of fatal outcome.

We studied 109 consecutive patients admitted to the HUCFF-UFRJ in the acute phase of BI, in order to discover the factors that independently affect early survival. In all patients the diagnosis was confirmed by cranial computed tomography (CT).

\section{SUBJECTS AND METHODS}

Data from one-hundred-and-nine hospitalized patients older than 20 years of age were consecutively collected along 1986 and 1987. A retrospective study was them carried out. All patients were admitted within one week of onset of disease. Diagnosis of the stroke syndrome followed accepted rigid clinical criteria ${ }^{4}$, and was made in the presence of an acute onset ( $\leq 48$ hours) of neurological deficit not associated with trauma or other obvious diagnosis, lasting more than 24 hours or until death, and occurring in the last week. Patients with severe neurological insults are preferentially admited to our hospital. An initial CT was always required for admission to study.

Strokes were classified according to causal mechanisms considering the neurological and medical history, neurological symptoms and signs, CT and, when available, findings from electrocardiogram (ECG), echocardiogram, ultrasound and angiographic studies of cervical arteries. To discriminate large-artery atherothrombosis (ATH) from embolic brain infarction (EMB), we used classification criteria adapted from the National Survey of Stroke (NSS) ${ }^{38}$. CT excluded alternative diagnoses such as intracerebral or subdural hemorrhages, tumours. This eliminated various degrees of diagnostic uncertainty present in the original classification. ATH was diagnosed in the absence of specific criteria for EMB, lacunes (LAC) or other diagnoses. A normal angiogram or the absence of anatomically appropriate extra or intracranial arterial stenosis were considered exclusion criteria for ATH. EMB was diagnosed in the presence of a cardiac source of emboli-cardiac surgery or myocardial infarction within the last six weeks, valvular disease (including mitral valve prolapse), infeccious or marantic endocarditis, dilated congestive cardiomyopathy, atrial fibrillation or other supraventricular tachyarrhythmia, atrial mixoma and right-to-left cardiac shunts. As in the NSS, cases of BI associated with irregular or ulcerated carotid plaques (as assessed by carotid ultrasound or angiogram) were also classified as EMB. Mohr and coworkers ${ }^{24}$ suggested that over $20 \%$ of BI cases of cardioembolic origin may exhibit a gradual onset. This is in contrast with a large and detailed autopsy study suggesting that such gradual onset is extremely rare, at least in fatal cases. In the absence of routine and early angiographic evaluation, we created a class of "infarctions of undetermined cause" (IUC) composed of patients with a cardiac source of emboli but exhibiting a gradual ( $>6$ hours) onset of symptoms and signs before hospitalization. LAC was diagnosed in the presence of a classical lacunar syndrome and a normal $C T$ or a small $(\leq 20 \times 20 \times 20 \mathrm{~mm})$ pontine or deep hemispheric infarct on $\mathrm{CT}^{12,30}$. The OTHER category included arteritis of diverse etiologies, arterial dissection, migraine-related stroke, venous infarctions and other unusual causes of BI.

We studied the univariate influence of the factors listed in Table 1 on the probability of early death (within 30 days of admission). Proportions of patients reaching this end-point were studied by chi-square ( $\aleph$ ) or Fisher's exact method.P values $\leq 0.05$ were considered significant. Missing data were present in the study of some variables, e.g. aphasia or urinary incontinence were only analysed in lucid patients; results of complementary exams were only entered when obtained within $\mathbf{7 2}$ hours of admission. All variables were then entered into a proportional hazard model based on backward elimination stepwise regression (Statistical Package for Social Sciences, SPSS ${ }^{26}$ ), with death within 30 days as the dependent variable. We also studied separately lucid patients on admission and those with any degree of impairment of consciousness with a similar procedure. Our final aim was the construction of a simple prognostic algorythm which could predict the chances of survival in different subgroups of patients.

A detailed description of the entire series of 109 patients may be found elsewhere ${ }^{3}$. In summary, there were $65(59.6 \%$ ) white patients; $59(54.1 \%)$ were men. The age on admission for all patients (mean $\pm 1 \mathrm{sd}$ ) was $57 \pm 17$ (men $58 \pm 16$; women $55 \pm 18$ ). There were 18 patients $\leq 40$ years old ( 11 women; $10 \mathrm{EMB})$. Most patients had associated previous diagnoses: $66(60.6 \%)$ arterial hypertension (AH); 17 (15.6\%) diabetes mellitus (DM); $49(45 \%)$ diverse cardiopathies, mostly rheumatic valvar disease and congestive heart failure (CHF) (13 cases each) and ischemic heart disease ( 12 cases). The BI was recurrent (occurring more than three weeks after an initial stroke ${ }^{37}$ ) in 14 cases. In 22 the BI followed one or more transient ischemic attacks. Most cases (98) involved the supratentorial (ST) compartment. The final diagnosis was ATH in 50 cases (45.9\%); EMB in 40 (36.7\%); IUC in 6 (5.5\%); LAC in 7 
Table 1. Clinical variables accessed in 109 cases of brain infarction.

\begin{tabular}{|c|c|c|}
\hline 1 - DEMOGRAPHIC FACTORS & - RESPIRATORY PATTERN + & 6 - LABORATORY FINDINGS \\
\hline AND PREVIOUS MEDICAL & · BRAINSTEM REFLEXES + & \\
\hline HISTORY & $\begin{array}{l}\text { CONJUGATE EYE } \\
\text { DEVIATION++ }\end{array}$ & $\begin{array}{l}\text { - HEMATOCRIT / HEMOGLOBIN } \\
\text { - both sexes }\end{array}$ \\
\hline$\cdot$ RACE & - MOTOR DEFICIT ++ & - men \\
\hline$\cdot \mathrm{AGE}$ & - any degree & - women \\
\hline - SEX & - partial vs massive & \\
\hline - CARDIAC DISEASE & & · TOTAL LEUCOCYTE COUNT \\
\hline - any type & - BABINSKI SIGN ++ & · GLYCEMIA \\
\hline - congestive & - uni or bilateral & $\cdot$ UREA \\
\hline $\begin{array}{l}\text { - hypertensive } \\
\text { - ischemic }\end{array}$ & - uni vs bilateral & $\begin{array}{l}\cdot \text { CREATININE } \\
\cdot \text { SODIUM }\end{array}$ \\
\hline - rheumatic & - WALKING ABILITY +++ & \\
\hline - infectious & . APHASIA +++ & \\
\hline - other & $\begin{array}{l}\cdot \text { VISUAL FIELD DEFECT +++ } \\
. \text { SPHINCTER CONTROL }\end{array}$ & 7 - X-RAY AND ECG FINDINGS \\
\hline - DIABETE MELLITUS & LOSS +++ & · X-RAY ABNORMALITIES \\
\hline - ARTERIAL HYPERTENSION & - SENSORY DISTURBANCE +++ & - acute pneumonia \\
\hline - PREVIOUS STROKE & . OTHER FINDINGS & - cardiac disease \\
\hline ATTACK & 4 - SEQUENCIAL & - other \\
\hline $\begin{array}{l}\text { - any type } \\
\text { - unique vs multiple }\end{array}$ & NEUROLOGICAL EXAM & $\begin{array}{l}\text { - ECG ABNORMALITIES } \\
\text { - any type }\end{array}$ \\
\hline - recent vs remote & $\begin{array}{l}\text { - LEVEL OF CONSCIOUSNESS } \\
\text {. CHANGES OF LEVEL OF }\end{array}$ & $\begin{array}{l}\text { - cardiac arrhythmia } \\
\text { - ischemia }\end{array}$ \\
\hline . CHRONIC OBSTRUCTIVE & CONSCIOUSNESS & - conduction block \\
\hline $\begin{array}{l}\text { PULM. DIS. } \\
\text {. CHRONIC RENAL FAILURE }\end{array}$ & . CHANGES OF FOCAL SIGNS & $\begin{array}{l}\text { - ventricular strain } \\
\text { - others }\end{array}$ \\
\hline - ALCOHOLISM & 5 - INITIAL CLINICAL EXAM & 8 - FINAL DIAGNOSES \\
\hline 2 - CLINICAL PRESENTATION & $\begin{array}{l}\text { - BLOOD PRESSURE } \\
\text { - diastolic }\end{array}$ & ETHIOLOGY \\
\hline $\begin{array}{l}\text { - TIME FROM ONSET TO } \\
\text { ADMISSION }\end{array}$ & - systolic & $\begin{array}{l}\text { - large artery atherothrombosis } \\
\text { - cerebral embolism }\end{array}$ \\
\hline - PERI-OPERATIVE ONSET & - CARDIAC ARRHYTHMIAS & - lacunar infarct \\
\hline - EARLY LOSS OF & - any type & - other \\
\hline $\begin{array}{l}\text { CONSCIOUSNESS } \\
\cdot \text { SEIZURES }\end{array}$ & $\begin{array}{l}\text { - rapid supraventricular } \\
\text { arrhythmias }\end{array}$ & - undetermined \\
\hline $\begin{array}{l}\cdot \text { HEADACHE } \\
\cdot \text { ONSET }\end{array}$ & - others & $\begin{array}{l}\text { - TOPOGRAPHY } \\
\text { - supra vs infratentorial }\end{array}$ \\
\hline - gradual ( $>6$ hours) vs rapid & $\begin{array}{l}\text { CONCURRENT ACUTE } \\
\text { DISEASES } \\
\text { - any type }\end{array}$ & 9 - TREATMENT \\
\hline $\begin{array}{l}3 \text { - INITIAL NEUROLOGICAL } \\
\text { EXAM }\end{array}$ & $\begin{array}{l}\text { - pneumonia } \\
\text { - cardiac failure } \\
\text { - others }\end{array}$ & $\begin{array}{l}\text { - SUPPORTIVE MEASURES } \\
\text { - ANTICOAGULATION } \\
\text { - PROPHYLATIC HEPARIN }\end{array}$ \\
\hline $\begin{array}{l}\text { LEVEL OF CONSCIOUSINESS } \\
\text { normal vs altered vs coma } \\
\text {. GLASGOW COMA SCALE + } \\
\text {. PUPILLARY DISFUNCTION + }\end{array}$ & $\begin{array}{l}\text { OTHER CONCURRENT } \\
\text { DISEASES } \\
\text { - peripheral arterial disease } \\
\text { - carotid artery disease }\end{array}$ & $\begin{array}{l}\text { ASPIRIN } \\
\text { OSMOTIC THERAPY } \\
\text { CORTICOSTEROIDS }\end{array}$ \\
\hline
\end{tabular}

$+\quad$ only patients with impaired consciousness on admission

+ all cases and in patients with or without impaired consciousness on admission

+++ only lucid patients on admission 
Table 2. Factors increasing early death risk after brain infarct.

\begin{tabular}{|c|c|c|c|}
\hline MEDICAL HISTORY & & SEQUENCIAL NEUROLOGICAL & \\
\hline - Congestive Heart Failure & $\mathrm{p}=0.053$ & EXAM & \\
\hline - Perioperative stroke & $\mathrm{p}=0.011$ & - Impaired Consciousness & \\
\hline - Inhospital stroke & $\mathrm{p}=0.027$ & $\begin{array}{l}\text { - Any degree } \\
\text { - Coma (vs lesser degrees) }\end{array}$ & $\begin{array}{l}\mathrm{p}=0.002 \\
\mathrm{p}=0.039\end{array}$ \\
\hline INITIAL NEUROLOGICAL EXAM & & - Lesser degrees (vs normal) & $\mathrm{p}=0.022$ \\
\hline - Impaired Consciousness & $\mathrm{p}=0.03$ & - Deterioration to Coma (in patients with & \\
\hline (any degree) & & lesser degrees of impairment) & $p=0.044$ \\
\hline - In Patients With Impaired & & - Worsening of Motor Deficit to Plegia & $\mathrm{p}=0.011$ \\
\hline Consciousness & & - Appearance of Uncal Herniation & $\mathrm{p}=0.055$ \\
\hline - Brainstem Disfunction & $\mathrm{p}=0.066$ & & \\
\hline · Babinski Sign & $\mathrm{p}=0.033$ & INITIAL CLINICAL EXAM & \\
\hline - Bilateral Babinski Sign & & - Arterial Hypotension & $\mathrm{p}=0.029$ \\
\hline vs normal & $\mathrm{p}=0.011$ & - Cardiac Arrhythmia (other than & \\
\hline $\begin{array}{c}\text { - All patients } \\
\text { - Babinski Sign }\end{array}$ & $\mathrm{p}=0.009$ & supraventricular tachyarrhythmia*) & $\mathrm{p}=0.053$ \\
\hline - Bilateral Babinski Sign & & COMPLEMENTARY EXAMS & \\
\hline vs unilateral & $p=0.09$ & · High Hemoglobin Level & \\
\hline vs normal & $\mathrm{p}=0.017$ & vs low level & $\mathrm{p}=0.032$ \\
\hline \multirow{4}{*}{$\begin{array}{l}\text { Unilateral Babinski Sign } \\
\text { vs normal }\end{array}$} & & vs normal & $\mathrm{p}=0.046$ \\
\hline & $\mathrm{p}=0.038$ & & \\
\hline & & DRUG THERAPY & \\
\hline & & Corticosteroids & $p=0.034$ \\
\hline
\end{tabular}

* Frequent ventricular ectopic beats, bi-trigeminism, and one patient with complete atrioventricular block

Most patients $(70.6 \%)$ were admitted within 24 hours of disease onset ( 59 cases) or were already hospitalized for other medical/surgical reasons ( 18 cases, 5 perioperative infarcts; $12 \mathrm{EMB}$ ). Eleven patients exhibited motor seizures at onset. An initial blood pressure record of $140 / 90 \mathrm{~mm} \mathrm{Hg}$ or more was present in 68 patients (63\%), cardiac arrhythmias (especially atrial fibrillation and frequent ventricular ectopic beats) in 31 (28.4\%), and CHF in $13(11.9 \%)$. At the first neurological examination, 103 patients $(94.5 \%)$ exhibited motor deficit (plegia of at least one limb in 46). Fifty-six patients (51.4\%) had an altered level of consciousness (including 43 of 77 evaluated in the first 24 hours); nine were comatose, and 47 presented with minor degrees of loss of consciousness (confusional states, delirium, hipersonia or stupor). Twenty of these 56 patients (35.7\%) already exhibited altered pupillary function, respiratory patterns or brainstem reflexes, all suggesting additional brainstem dysfunction. Among lucid patients, $33.6 \%$ (21) were aphasic, $24.5 \%$ (13) had lost sphincter control, and $47.5 \%$ (19 of 40 evaluated) could not walk. One patient died on the first day, from massive hemispheric infarction. After 48-72 hours of in-hospital observation, impairment of consciousness was present in 51 patients (47.2\%), including 13 in coma. Many patients exhibited worsening of focal signs (19), especially motor deficit, or the development of uncal herniation (7).

\section{RESULTS}

Thirty-four patients (31.2\%) died during hospitalization, 26 (23.9\%) in the first 30 days following admission. Most deaths (18) occurred in the first 15 days. Deaths within 30 days were mainly related to the severity of the neurological insult- 11 cases (10 ST strokes). Eight of these deaths occurred in the first week. Cardiovascular and infectious complications were responsible for 8 and 7 deaths respectively, and were more evenly distributed. All 8 late deaths ( $>30$ days) were related to infection ( 4 cases, all from nosocomial pneumonia) or constituted sudden unexpected events (cardiac arrhytmias or massive pulmonary embolism).

Table 2 shows the results of univariate analysis. No demographic or stroke risk factor was statistically important. Women exhibited a slightly higher case-fatality rate (30\% vs. $18 \%$ ). EMB was more commonly diagnosed in women ( $48 \%$ vs $27.1 \%, \times \mathrm{p} 0.039$ ) as well as impairment of consciousness at the first neurological exam (62\% vs $42.4 \%, \propto \mathrm{p} 0.064)$.This suggests that women frequently suffered more serious strokes.

Patients admitted between 3 and 7 days after stroke onset exhibited a low fatality rate (6.3\%). Patients with in-hospital strokes fared badly ( $44.5 \%$ early case-fatality rate). Most (11) were admitted for medical or surgical 
Table 3. Factors independently related to increased 30-day case fatality rate in 109 cases of acute brain infarction: multiple regression analysis.

\begin{tabular}{lll}
\hline \multicolumn{1}{c}{ Adverse Factor } & \multicolumn{1}{c}{ Beta } & $\mathrm{p}$ Value \\
\hline \hline Coma After 48-72 hours & 0.50533 & $\mathrm{p}=0.0003$ \\
Inhospital Stroke & 0.26543 & $\mathrm{p}=0.014$ \\
Bilateral Babinski Sign & 0.31767 & $\mathrm{p}=0.0326$ \\
Uni or Bilateral Babinski Sign & 0.16488 & $\mathrm{p}=0.033$ \\
Minor Degrees of Impairment of & 0.1973 & $\mathrm{p}=0.0396$ \\
Consciousness After 48-72 Hours & & \\
& & \\
Large-artery Atherothrombosis & 0.20498 & $\mathrm{p}=0.0528$ \\
Cerebral Embolism & 0.19577 & $\mathrm{p}=0.0724$ \\
Early Loss of Consciousness & 0.16941 & $\mathrm{p}=0.073$ \\
Cardiac Failure & 0.19738 & $\mathrm{p}=0.0976$ \\
\hline
\end{tabular}

MULTIPLE R=0.55019; $F$ VALUE $=4.77527$; SIGNIF

$\mathrm{F}=0.0001$; (FURTHER STATISTICAL DATA ARE

AVAILABLE UPON REQUEST) treatment of diverse cardiopathies and symptomatic carotid stenosis. Early impairment of consciousness in 13 cases $(72.2 \%$ ). Most deaths in this group (6 of 8) were directly related to progressive neurological deterioration (PND).

Massive motor deficit (no displacement of any segment of one or more limbs)and the presence of the Babinski sign were associated with a worse outcome. A low fatality rate was observed in lucid patients with flexor plantar responses $(7.7 \%)$ or with dimidiated hyposthesia (4.8\% vs $28.4 \%, \kappa \mathrm{p} 0.045$ ).

Predictions based on the level of consciousness were more reliable when made 48-72 hours after admission. At that time, any degree of disturbance was associated with a fourfold reduction of the chances of survival. The fatality rate of comatose patients was significantly different from that of patients with lesser degrees of disturbance (such differences were not so obvious on admission).

Patients who recovered from initial depression of the level of consciousness fared well (7.7\% early fatality rate), as well as those 19 who exhibited partial regression of motor deficit (no deaths).

Hyperglycemia in nondiabetic patients was associated with a nonsignificant reduction of survival rates. We could not directly evaluate its possible adverse effects in diabetic patients, as all had hyperglycemia on admission. Myocardial injury on admission through ECG ( 3 cases) was always associated with early death. Four other patients with acute myocardial infarct had a good initial evolution, however. The use of dexamethasone was associated with death in 5 of 9 cases.

The multiple regression procedure for all patients (Table 3) again revealed the level of consciousness after 48-72 hours as the main prognostic predictor.Extensor plantar reflexes had an independent adverse effect. BI during hospitalization for other causes was highly predictive of a bad evolution. Although not evident on univariate analysis, the potential impact of cardiac failure on admission was now demonstrated.

We analysed patients with any degree of loss of consciousness on admission (Table $4 \mathrm{~A}$ ). The presence of coma after the second day of hospitalization and the finding of the Babinski sign had important prognostic impact. In lucid patients on admission (Table 4B) a history of CHF was the only factor predicting an increased early fatality rate.

The main prognostic factors after BI are, therefore, quite different in patients who are or not lucid on admission (Table 4, Figure 1). The former usually have high hospital survival rates, except in the presence of CHF. In patients with depressed sensorium, the algorythm stresses the importance of their level of consciousness by the third day after admission.

\section{COMMENTS}

The high case fatality rate detected in this and some other studies is probably a reflexion of the initial clinical status of our patients, as suggested by Térent and Andersson $^{37}$. The time course of hospital deaths and the proportion of patients dying from PND, cardiovascular and infectious complications were comparable to reported
Table 4. Factors independently related to increased 30-day case fatality rate in acute brain infarction in patients with or without impairment of consciousness on admission: multiple regression analysis.

\begin{tabular}{lcc}
\hline \multicolumn{1}{c}{ Adverse Factor } & Beta & $\mathrm{p}$ Value \\
\hline \hline A. Impaired Consciousness on & & \\
Admission (N=56) & & \\
Coma After 48-72 Hours & 0.34397 & $\mathrm{p}=0.0152$ \\
Unilateral Babinski Sign & 0.46209 & $\mathrm{p}=0.0269$ \\
\hline
\end{tabular}

MULTIPLE $R=0.44513 ; F$ VALUE $=6.54834 ;$ SIGNIF $F=0.0029$

B. Lucid Patients $(\mathrm{N}=53)$

History of Congestive Heart

Failure

$0.37755 p=0.0434$ 
ON ADMISSION

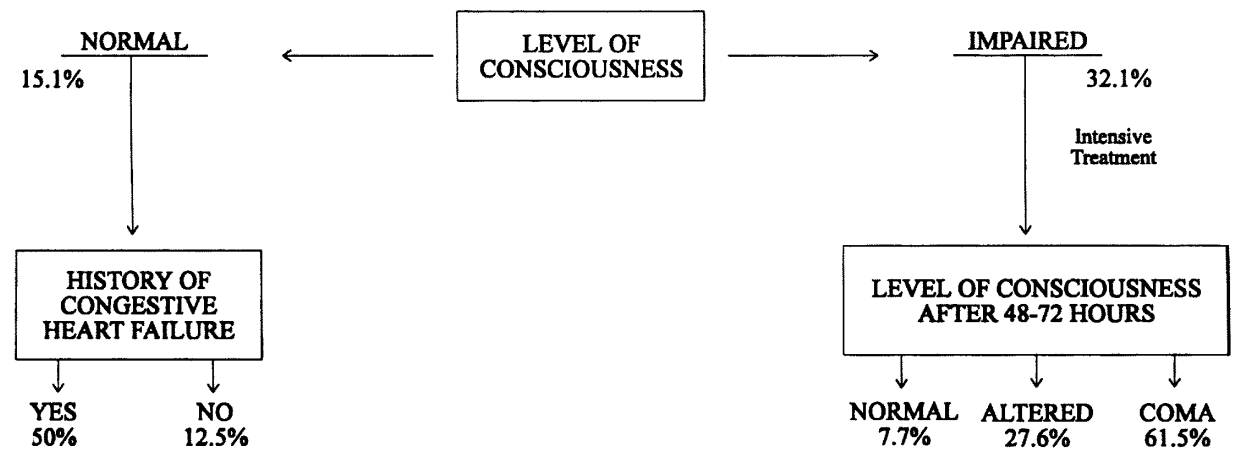

Fig 1. Prognostic algorythm for patients with acute brain infarction.

studies ${ }^{5,36}$. Some deaths related to clinical complications should be considered as terminal events in already critically ill patients ${ }^{36}$.

Our case fatality rate for patients $\leq 40$ years (23.9) is higher than shown in previous reports on children ${ }^{35}$ or young adults ${ }^{16}$. It probably reflects a close association between BI and serious cardiac diseases. Ten patients suffered EMB strokes. This has been related to greater lesion extension, hemorrhagic changes, early reperfusion and other factors leading to increased mass effect ${ }^{9,17,20,27}$. Accordingly, 3 of the 5 deaths in this group were due to PND, the others being related to acute bacterial endocarditis (one immediatly after emergency surgery).

Our finding of a nonsignificant difference in outcome between patients with EMB and ATH is in contrast with previous reports ${ }^{15.39}$. EMB is frequently associated with greater neurological lesions. This probably explains why the independent predictive value of the diagnosis of EMB partially vanishes when variables directly assessing severity are included in the multiple regression analysis.

The close association between disturbances of the level of consciousness, especially coma, and outcome of acute stroke has long been recognized ${ }^{11,22,31}$ and continues to be demonstrated in recent years ${ }^{1,10,14,28,29}$. The high fatality rate associated with such disturbances is closely related to the extension and critical topography of the neurological insult and to the development of massive cerebral edema. However, extraneurological factors, such as reduced cardiac output and metabolic derangements, may contribute or entirely explain the impairment of consciousness. In our study, recovery within 48-72 hours was not rare and was associated with increased survival rates. Clearly, early correction of extraneurological factors and anti-edema therapy in selected cases are necessary.

The analysis of the level of consciousness after two or three days of admission has a high predictive value in respect to the clinical outcome. The close association between prolonged and deep coma and the outcome after stroke has been suggested by Gowers (cited by Marquadsen ${ }^{22}$ ) as early as in 1886 , and was later confirmed ${ }^{31}$. Carter, cited by Robinson and cowokers $^{34}$, found a fatality rate of $44 \%$ after 24 hours of coma, and of almost $90 \%$ after more than 48 hours. After this period, most reversible associated factors will be corrected, and most patients who are still obtunded or comatose have suffered extensive neurological lesions.

The adverse prognostic influence of CHF has been described previously ${ }^{23,33,34}$, but is not an uniform finding ${ }^{2,28}$. Our results indicate that an admission X-ray suggesting CHF or cardiomegaly is also important: early death in $29.6 \%(8 / 27)$ vs $13 \%(6 / 46)$. Aside the possible association with an embolic etiology of stroke and a higher risk of development of fatal arrhythmias and pulmonary embolism, the increased death risk in patients with CHF is probably related to the reduction of 
cardiac output and cerebral blood flow. This reduction, even in the absence of an acute neurological insult, may lead to a decreased level of consciousness ${ }^{32}$ and focal brain damage ${ }^{19}$.

Cardiovascular complications are a common cause of death in the acute phase of stroke $\mathrm{e}^{5,21}$, even in patients with small functional deficits ${ }^{22,36}$. Detection of diverse arrhythmias on admission has been related to increased fatality rates in some ${ }^{19,23,25,36}$ but not all ${ }^{2,37}$ studies. In our series, most deaths in patients with ventricular ectopic beats were related to PND. In patients with severe neurological insults, ectopic beats may reflect marked sympathetic stimulation. On the other hand, two patients in this group suffered sudden deaths. Acute pulmonary embolism could not be excluded in these cases. However, ventricular extrasystolic beats even without classical ECG warning patterns (frequent or multifocal beats, $\mathrm{R}$ on $\mathrm{T}$ phenomenon, runs of ventricular tachycardia) may well constitute a warning sign for lethal cardiac arrhytmias in the context of acute stroke.

In summary, the present study suggests that the death risk following acute $\mathrm{BI}$ may be predicted by the analysis of some easily assessed clinical variables. Patients without cardiac failure who are lucid three days after admission probably do not benefit from further hospitalization. the text.

Aknowledgements - We wish to thank Drs. Ayrton R. Massaro and Maurice B. Vincent for critical review of

\section{REFERENCES}

1. Ahmed OI, Orchard TJ, Sharma R, Mitchell H, Talbot E. Declining mortality from stroke in Allegheny County, Pennsylvania: trends in case fatality and severity of disease, 1971-1980. Stroke 1988, 19: 181-184.

2. Allen CMC. Predicting the outcome of acute stroke: a prognostic score. J Neurol Neurosurg Psychiatry 1984, 47: 475-480.

3. André C. A morte na fase aguda do infarto cerebral: cronologia e causas de óbito e determinação dos fatores prognósticos adversos. Thesis. Rio de Janeiro: UFRJ, INDC, 1991.

4. Arbin MV, Britton M, Faire U, Helmers C, Miah K, Murray V. Validation of admission criteria to a stroke unit. J Chron Dis 1980, 33: 215-220.

5. Bounds JV, Wiebers DO, Whisnant JP, Okazaki H. Mechanisms and timing of deaths from cerebral infarction. Stroke 1981, 12: 474-477.

6. Britton M, Faire U, Helmers C, Miah K. Prognostication in acute cerebrovascular disease: subjective assessment and test of a prognostic score. Acta Med Scand 1980; 207:37-42.

7. Candelise L, Pinardi G, Morabito A, et al. Mortality in acute stroke with atrial fibrillation. Stroke 1991;22: 169-174.

8. Caronna JJ, Levy DE. Clinical predictors of outcome in acute stroke. Neurol Clinics 1983, 1: 103-117.

9. Cerebral Embolism Study Group. Immediate anticoagulation of embolic stroke: a randomized trial. Stroke 1983, 14: 668-676.

10. Chambers BR, Norris JW, Shurvell BL, Hachinski VC. Prognosis of acute stroke. Neurology 1987, 37: 221-225.

11. Daalsgaard-Nielsen T. Some clinical experiences in the treatment of cerebral apoplexy (1000 cases). Acta Psychiatr Scand 1956, Suppl.1: 101-109.

12. Fisher CM. Lacunar strokes and infarcts: a review. Neurology 1982, 32: 871-876.

13. Front D, Frankel A, Israel O, Ahaon Y, Satinger A, Linn S. Ejection fraction response of the left ventricle of the heart to acute cerebrovascular accident in patients with coronary artery disease. Stroke 1986, 17: 613-616.

14. Hatano S. Experience from a multi-centre stroke register: a preliminary report. Bull.WHO 1976, 54: 541-553. 15. Herman B, Leyten ACM, Luijk JH, Frenken CWGM, Op de Coul AAW, Schulte BPM. Epidemiology of stroke in Tilburg, The Netherlands. The population-based stroke incidence register: 2. Incidence, initial clinical picture and medical care, and three-week case fatality. Stroke 1982, 13:629-634.

16. Hindfelt B, Nilsson O. The prognosis of ischemic stroke in young adults. Acta Neurol Scand 1977, 55: 123-130.

17. Hornig CR, Dorndorf W, Agnoli AL. Hemorrhagic cerebral infarction: a prospective study. Stroke 1986, 17: 179-185.

18. Jorgensen L, Torvik A. Ischaemic cerebrovascular diseases in / an autopsy series: part 2. Prevalence, location, pathogenesis, and clinical course of cerebral infarcts. J Neurol Sci 1969, 9: 285-320.

19. Lavy S, Stern S, Melamed E, Cooper G, Kerem A, Levy P. Effect of chronic atrial fibrillation on regional cerebral blood flow. Stroke 1980, 11: 35-38.

20. Lodder J, Krijne-Kubat B, Broekman J. Cerebral hemorrhagic infarction in autopsy: cardiac embolic cause and the relationship to the cause of death. Stroke 1986, 17: 179-185.

21. Lowe GDO, Jaap AJ, Forbes CD. Relation of atrial fibrillation and high haematocrit to mortality in acute stroke.

Lancet 1983, 1: 784-786. 
22. Marquadsen J. The natural history of acute cerebrovascular disease: a prospective study of 769 patients. Acta Neurol Scand 1969, 45 (Suppl 38): 1-192.

23. Miah K, Arbin MV, Britton M, Faire U, Helmers C, Maasing R. Prognosis in acute stroke with special reference to some cardiac factors. J Chron Dis 1983, 36: 279-288.

24. Mohr JP, Caplan LR, Melski JW, et al. The Harvard cooperative stroke registry: a prospective registry. Neurology 1978, 28: 754-762.

25. Norris JW, Froggatt GM, Hachinski VC. Cardiac arrhytmias in acute stroke. Stroke 1978, 9: 392-396.

26. Norusis MJ. SPSS/PC TR: SPSS for the IBM PC/XT. Chicago: SPSS, 1984.

27. Ott BR, Zamani A, Kleefield J, Funkenstein HH. The clinical spectrum of hemorrhagic infarction. Stroke 1986, 17: 630-637.

28. Oxbury JM, Greenhall RCD, Grainger KMR. Predicting the outcome of stroke: acute stage after cerebral infarction. Br Med J 1975, 3: 125-127.

29. Patrick BK, Ramirez-Lassepas M, Snyder BD. Temporal profile of vertebrobasilar territory infarction: prognostic implications. Stroke 1980, 11: 643-648.

30. Pullicino P, Nelson RF, Kendall BE, Marshall J. Small deep infarcts diagnosed on computed tomography. Neurology 1980, 30: 1090-1096.

31. Rankin J. Cerebral vascular accidents in patients over the age of 60: II Prognosis. Scott Med J 1957; 2: 200-215. 32. Reed RL, Siekert RG, Merideth J. Rarity of transient focal cerebral ischemia in cardiac dysrhyt $2 \mathrm{~h} 1 \mathrm{mia}$. JAMA 1973, 223: 893-895.

33. Robinson RW, Cohen WD, Higano N, et al. Life-table analysis of survival after cerebral thrombosis. Ten-year experience. JAMA 1959, 163: 1149-1152.

34. Robinson RW, Demirel M, LeBeau RJ. Natural history of cerebral thrombosis nine to nineteen year follow-up. J Chron Dis 1968, 21: 221-230.

35. Schoenberg BS, Mellinger JF, Schoenberg DG. Cerebrovascular disease in infants and children: a study of incidence, clinical features, and survival. Neurology 1978, 28: 763-768.

36. Silver FL, Norris JW, Lewis AJ, Hachinski VC. Early mortality following stroke: a prospective review. Stroke 1984, 15: 492-496.

37. Térent A, Andersson B. The prognosis for patients with cerebrovascular stroke and transient ischemic attacks. Upsala J Med Sci 1981, 86: 63-74.

38. Walker AE, Robins M, Weinfield FD. Clinical findings. In: Weinfield FD (ed.). The national survey of stroke. Stroke 1981, 12 (Suppl 1): 13-44.

39. Whisnant JP, Fitzgibbons JP, Kurland LT, Sayre GP. Natural history of stroke in Rochester, Minnesota, 1945 through 1954. Stroke 1971, 2: 11-22. 